\title{
Contractualism and Poverty Relief
}

\section{Introduction}

More than a billion people live today in extreme poverty. 18 million, most of them children, die every year due to poverty-related causes. At the same time, we witness an unprecedented accumulation of wealth and technological capabilities in the hands of affluent people in industrialized countries. It is possible, and indeed not very expensive, for the world's rich to assist the world's poor to end their ruinous destitution. Do they have a duty to do so? What kind of duty do they have? Is it a weak and discretionary one or is it strong and strict? Is it only an individual and informal duty of beneficence or is it also a collective and institutionally enforceable duty of justice? In this paper I consider how a particular moral theory might help us to answer these questions. According to T.M. Scanlon's contractualism, "an act is wrong if its performance under the circumstances would be disallowed by any set of principles for the general regulation of behavior that no one could reasonably reject as a basis for informed, unforced general agreement." Even though it is obvious that the world's rich could not justify to the world's destitute their failure to assist them, it is not so obvious what kind of duty they have. I will argue that the kind of duty that the world's rich have should not be primarily construed, as is often done, as an informal duty of beneficence by isolated individuals, but as an obligation to contribute to an institutional scheme promoting basic economic justice. I proceed as follows. First, I clarify the structure of contractualist reasoning (section 2). Next, I reconstruct Scanlon's discussion of assistance in What We Owe to Each Other (sections 3.1-3.2), show that it is insufficient (section 3.3), and explain how it can be elaborated further by shifting from considerations of beneficence to considerations of justice (section 3.4). Finally, I consider some important objections to, and implications of, the approach developed here (section 4).

I argue that contractualism provides a promising way of conceiving the demands of poverty relief because of its capacity for grounding a

\footnotetext{
'T.M. Scanlon, What We Owe to Each Other (Cambridge, Mass.: Harvard University Press, 1998), p. 153 (hereafter “WWO" followed by page numbers).
}

(C) Copyright 2007 by Social Theory and Practice, Vol. 33, No. 2 (April 2007) 
compelling connection between individuals' moral reasons and concerns about larger injustices. Before I proceed, I should answer an obvious initial objection to the project of this paper. The objection is that Scanlon's contractualism simply is not concerned with issues of social justice, but with broader ones of interpersonal morality. Scanlon himself says that his theory is, for example, different from Rawls's in that he does not focus on "principles of justice" applied to the basic structure of society but on "principles of individual conduct" (WWO 228). However, Scanlon also says that his account of contractualist justification can be "tightened" in order to account for more specific contexts (such as those of justice) (WWO 246). ${ }^{2}$ In this paper I pursue such a "tightening." It will become clear in the course of the argument that follows that this tightening is not only possible, but also necessary on general contractualist reasons. I will show that a direct consideration of institutional justice is required once the moral reasons for poverty relief, and the factual difficulties encountered in honoring them, are taken seriously.

\section{Scanlon's Contractualism}

Scanlon's contractualism provides an answer to two fundamental questions in moral philosophy. The first is "What standard should we use in order to decide whether an act is wrong?" and the second is "What is the source of motivation for complying with what morality requires?"

Scanlon's Contractualist Standard answers the first question as follows: "[A]n act is wrong if its performance under the circumstances would be disallowed by any set of principles for the general regulation of behavior that no one could reasonably reject as a basis for informed, unforced general agreement" ( $W W O 153$; see also 4).

Scanlon's Contractualist Ideal answers the second question as follows: "What is basic to contractualism ... is the idea of justifiability to each person (on grounds that he or she could not reasonably reject)" ( $W W O 390$, n. 8; see also 168-69).

The Contractualist Standard and the Contractualist Ideal are tightly connected. In fact, Scanlon claims that his construal of contractualism is superior to others precisely because it elucidates the connection between moral assessment and moral motivation: our moral assessments of acts should track the interpersonal justifiability of the principles used to back them precisely because what moves us to act morally is the concern to be

\footnotetext{
${ }^{2}$ Scanlon also says that "unlike Rawls," he sees "political philosophy (specifically, questions of justice) as a subdivision of moral philosophy rather than as a 'freestanding' subject." "Tolerance, Reasonableness, Contractualism, and International Justice: An Interview with Thomas M. Scanlon," Imprints 8, no. 2 (2005): 102-11, at p. 108.
} 
able to justify our actions to others. The search for mutually justifiable principles expresses our care for standing with each other in relations of "mutual recognition" (WWO 162).

A full explication of Scanlon's contractualism is beyond the scope of this paper. What is important for the discussion that follows is that we clarify some of the main features of the use of the Contractualist Standard. According to this standard, the wrongness of actions depends on whether the principles disallowing them could be reasonably rejected. I will mention here four features of the notion of reasonable rejection. First, judgments of reasonable rejection are always comparative (WWO $195,205)$. The assessment of a principle involves showing that it is superior or inferior to alternative ones. For example, to reasonably reject a principle $\mathrm{P} 1$ that allows for slavery is to endorse another alternative principle P2 that disallows it, and this amounts to claiming that the objections to the permission of slavery are stronger than the objections to its prohibition. Second, when deciding whether you must rely on P1 or P2, you should consider the standpoints of the individuals that would be affected by them. In the previous example, you should consider how individuals who might be slaves and individuals who might be slave-owners would be burdened or benefited by principles that allow for slavery and principles that do not. Principles are to be reasonably rejected only by reference to reasons that individuals have (WWO 229). Aggregative considerations of the kind favored by utilitarian moral theories are not basic. It would not do, for example, to say that the enslavement of a minority of the members of a society could not be reasonably rejected because it would produce a greater average or sum of well-being in that society than its absence. Individual slaves' well-being (or lack thereof) is simply not seriously taken into account by such a consideration.

A third important feature of reasonable rejection is that it appeals to what Scanlon calls "generic reasons." Since principles are supposed to apply to more than one particular case, when we consider how individuals would be affected by a principle we should not focus on the specific features of these individuals, but must instead rely on reasons that any individual facing similar circumstances can be expected to have (WWO 204). Thus, when we reject $P 1$, we may appeal to the fact that people have strong reason to want to be able to be in control of their lives (to choose whether, when, and where to work, for example). This is a generic reason that all individuals may be said to share, and thus one that seems appropriate to refer to when rejecting a principle allowing for slavery. It is important to notice that Scanlon acknowledges the fact that moral deliberation sometimes requires more rather than less attention to specific facts. A principle may be applied in different ways to different contexts. And some issues and contexts may merit the articulation of 
more local principles that need not hold elsewhere (WWO 341). Principles are not algorithmic rules to be applied uniformly, but general claims about the comparative status of certain reasons, and as such they "leave wide room for interpretation and judgment" (WWO 199). The articulation of principles is also a dynamic and fallible practice: "[W]e bring to moral argument a conception of generic points of view and the reasons associated with them which reflects our general experience of life, and ... this conception is subject to modification under the pressures of moral thought and argument" (WWO 205-6; see also 157).

A fourth feature of the use of the Contractualist Standard is that it assumes pluralism with respect to the kinds of considerations that go into the articulation of generic reasons. Well-being is, for example, an important consideration. But it is not the only one. Considerations of fairness and responsibility are also important (WWO 204, 213-18). My discussion of poverty relief will mainly focus on considerations of well-being, but some important arguments based on the ideas of fairness and responsibility will be relevant as well.

\section{Beneficence and Justice}

This paper focuses on the question of how contractualism might help us to identify and justify obligations on the part of the world's rich to assist the world's poorest to end their destitution. I will call these obligations basic positive duties. They are basic in the sense that their object is to contribute to the poor's access to necessities without which they cannot lead a minimally decent life (these include basic goods such as nutritious food, health care, housing, and education). And they are positive in the sense that their structure involves demands on the rich to actively provide the poor with what they need to achieve a minimally decent life. The thesis I will defend is that a proper contractualist account of the basic positive duties of the rich toward the extremely poor should primarily construe these duties as collective and enforceable duties of justice rather than as individual and informal duties of beneficence.

\subsection{An example}

To see what basic positive duties involve, it will be helpful to consider an example from the real world. Take Malawi's AIDS crisis. ${ }^{3}$ About 900,000 Malawians suffer from the deadly HIV virus. Their death can be easily prevented by a treatment with generic antiretroviral medicines that

\footnotetext{
${ }^{3}$ I rely on the account provided by Jeffrey Sachs, The End of Poverty (New York: Penguin, 2005), pp. 5-9.
} 
the Indian generic drug producer Cipla currently makes available through an arrangement with Malawi's government. This treatment costs $\$ 1$ per person per day. Presently, only about 400 people in Malawi are being served by this program. The problem is that in a country where incomes are approximately 50 cents per person per day (and where famine, malaria, and environmental disruptions are rampant), it is simply impossible for most of those facing the AIDS pandemic to pay for life-saving medicines. Malawi's government is unable to cover the massive costs to treat each AIDS sufferer. Its negotiations with international donors (including the European Union and the United States) and the Global Fund to Fight AIDS, TB, and Malaria ended in promises to fund assistance to only 25,000 people. The world's rich could, however, do more to help finance the medical treatment of Malawians. Do they have a duty to do so? What kind of duty would it be? How could it be justified?

\subsection{Scanlon's discussion of basic positive duties}

In his discussion of duties of aid, Scanlon applies the Contractualist Standard by engaging in a comparative consideration of alternative principles. Alternative principles of aid are assessed by comparing the weight of the generic reasons associated with the standpoints of those burdened and benefited by them ( $W W O 207)$. Scanlon proposes the following principle:

(A) Rescue: "[I]f you are presented with a situation in which you can prevent something very bad from happening, or alleviate someone's dire plight, by making only a slight (or even moderate) sacrifice, then it would be wrong not to do so" (WWO 224).

Scanlon explicates and defends this principle by comparing it with others. For example, (A) is different from

(B) Helpfulness: You ought to "take others' interests into account when [you] can very easily do so" (WWO 225).

(B) tells you to help others when no sacrifice at all would be involved (for example, if you hear about it, you should let a friend know about a job opening in her area of expertise). (A), on the other hand, demands some sacrifice (for example, giving up some money rather than merely making a phone call). The reason why (A) is more demanding than (B) is that its beneficiaries are people who are "in dire straits: their lives are immediately threatened, for example, or they are starving, or in great pain, or living in conditions of bare subsistence" (WWO 224). Scanlon thinks that $(A)$ could not be reasonably rejected. He shows this by comparing (A) with charity. The latter seems to involve the following principle: 
(C) Charity: Giving aid would be a good thing to do, but it would not be wrong not to do it (WWO 225).

In circumstances in which basic positive duties are considered, $(C)$ is too lenient. It praises those who assist others in need, but does not take them to have a duty to do so. Basic assistance becomes supererogatory, something that cannot be required. Clearly, people like the Malawians can reasonably reject (C) and demand (A) instead. The reason to avoid small sacrifices on the part of the well off is weaker than the worse off's reason to avoid extreme hardship. But how much can people like the Malawians demand from the world's rich? Scanlon acknowledges that " $[t]$ here may be stronger principles requiring a higher level of sacrifice" than (A) (WWO 224), but he does not mention any plausible candidate. Instead, he offers two kinds of considerations for seeing basic positive duties as imposing only slight or moderate sacrifices. ${ }^{4}$ The first is that when applying (A) we must understand it as taking "account of previous contributions (so that the principle does not demand unlimited sacrifice if it is divided into small enough increments)" (WWO 224). With this remark, Scanlon differentiates (A) from the familiar view advanced by Peter Singer. ${ }^{5}$ Since Singer seems to allow for an iterative approach to the comparison between the costs to the giver and the benefits for the recipient, his view is compatible with severe impoverishment of the well off, as each conceivable small contribution (up to the point of the agent's destitution) may, taken in isolation, involve much more benefit for the recipient than costs to the giver.

Second, Scanlon defends the limits involved in (A) by comparing it with the following, more demanding principle:

(D) "Intolerably Intrusive" Principle: In every decision that you make, you ought to give no more weight to your own interests than to similar interests of others (WWO 224).

This principle demands that we be impartial in each one of our actions, and thus that we never give special weight to our personal projects and relationships. (D) can, however, be reasonably rejected on impartial grounds. This is because, according to contractualism, when we assess a principle, we must not only consider the burdens imposed by it on agents in a particular occasion, but also the general burdens resulting from its

\footnotetext{
${ }^{4}$ Scanlon does not offer a metric to decide what counts as a "slight" or "moderate" sacrifice. He thinks the identification of such a metric depends on specific judgments when applying the contractualist framework to different circumstances (WWO 225).

${ }^{5}$ See Peter Singer, "Famine, Affluence, and Morality," Philosophy and Public Affairs 1 (1972): 229-43.
} 
adoption as a regular policy. A general cost of acceptance of (D) is the systematic intrusive disruption of personal projects and relationships. Since we have strong reason to value personal projects and relationships, a principle of aid that gives them no special weight would be one that we could reasonably reject. As a guide regarding aid, (A) is better than (D) because it can account for the importance of the personal point of view in the consideration of the sacrifices agents may be reasonably asked to shoulder in order to attend to the interests of others.

\subsection{Beneficence in nonideal contexts}

Does a conception of basic positive duties based on (A) suffice to account for all that would be needed to ensure significant poverty relief? This depends on whether we focus our attention on ideal or nonideal contexts. Ideal contexts are those in which there is full (or close to full) compliance with moral demands. Nonideal contexts are those in which there is only partial (and especially minimal) compliance. In ideal contexts (A) may suffice. If most of the world's rich complied with it, severe poverty could easily be eradicated. In our current world we do not, however, face an ideal context when we consider poverty relief. Most of the world's rich fall short of honoring (A). Some of them (call them the Conscientious Rich) do comply with (A), whereas most of them (call them the Careless Rich) do not. As we saw, Malawi's government could only get support for a program targeting a minuscule proportion of its dying population. Should the Conscientious Rich do more to help those who remain destitute as a result of the moral failures of the Careless Rich?

An answer to this question would require further development of the contractualist approach to account for nonideal contexts. Scanlon himself does not tell us how to proceed here (although he does say that contractualism can and should focus on these kinds of scenarios). ${ }^{6}$ It is important to notice that a principle that may not reasonably be rejected for an ideal

\footnotetext{
${ }^{6}$ See Scanlon, "Replies," Ratio 16 (2003): 424-39, p. 433. See also Philip Pettit, "Can Contract Theory Ground Morality?" in James Dreier (ed.), Contemporary Debates in Moral Theory (Malden, Mass.: Blackwell, 2006), pp. 77-96, at pp. 81-84. A strong case for the need for contractualism to account for nonideal contexts is presented by Thomas Pogge, "What We Can Reasonably Reject," Philosophical Issues 11 (2001): 118-47. For a pioneering discussion of contractualism and poverty relief in nonideal contexts, see Elizabeth Ashford, "The Demandingness of Scanlon's Contractualism," Ethics 113 (2003): 273-302. Ashford argues that given the comparative nature of reasonable rejection and the urgency of the claims of the poor, contractualism is potentially as demanding as utilitarianism. Even though I am not sure whether contractualism would indeed be as demanding as utilitarianism, I am sympathetic to Ashford's claim that contractualist argument would demand, under nonideal circumstances, that conscientious agents go beyond Scanlon's "Rescue" principle.
} 
context may be defective for guiding action in a nonideal one. For example, it would be wrong for me to engage in violent action when others are not violent. But it would not be wrong for me to be violent toward others who are aggressively violent toward me or others. In some cases, it may even be wrong for me not to be violent toward aggressors (such as when someone is trying to kill my son). A moral theory that seriously seeks to provide guidance for agents acting in the real world must introduce conditional clauses telling them not only what would be the right thing to do when (almost) everyone else would do it, but also what would be the right thing to do when (most, or sufficiently many) others would not do the first thing. ${ }^{7}$

A possibility is to supplement principle (A) with the following:

(E) Demanding Principle: Basic positive duties to rescue others may demand more than moderate sacrifices on your part if the moral significance of the benefits for those rescued clearly outweighs the moral significance of the costs you would incur.

This principle may suffice to demand what is necessary to secure poverty relief in conditions of minimal compliance. When (A) fails to do this due to the noncompliance of the Careless Rich, (E) may succeed by demanding that the Conscientious Rich fill the gap. ${ }^{8}$ Since the further sacrifice incurred by the Conscientious Rich is arguably less significant than the avoidance of death due to treatable diseases or starvation, the world's poorest (call them Destitute) have stronger reasons to reject a principle that permits the Conscientious Rich not to make further contributions than the latter have to reject (E). The generic reasons invoked by the Destitute trump the complaints voiced by the Conscientious Rich.

Principle (E) is not clear regarding the standard to be used when comparing costs to the Rich with benefits for the Destitute. A natural question is whether there is any cut-off point beyond which assistance to others cannot be demanded. It is difficult, however, to identify such a limit in a way that does not beg the question against the duty of beneficence. To say that such a duty may be very demanding is not to show that it is unjustifiable. This is why some authors try to show that we can identify some limits to the demands of beneficence that are internal to the

${ }^{7}$ I take the example regarding aggressive violence and the theoretical demand for conditional clauses (whose structure is "Do A, unless the number or proportion of Adoers is or will be below some threshold, in which case do B, or below some other
threshold, in which case do C") from Derek Parfit, Climbing the Mountain (unpubl. ms.), section 30 .

${ }^{8}$ (E) makes demands on all the rich, not just the conscientious ones. But when the careless do not act as they should (i.e., when the circumstances are nonideal), (E) yields more onerous responsibilities for the conscientious. 
very idea of beneficence.

An example is Garrett Cullity's recent proposal of the following principle: "If it is absurd to deny that your pursuing or having $x$ can ground requirements on others to help you, then your pursuing or having $x$ violates no requirement of beneficence." 9 Thus, for example, since it would be absurd to deny that your lack of access to food can ground requirements on me to help you, then your decision not to give up your food (if you have it) for the sake of someone else who is hungry would not be a failure to be beneficent on your part. Furthermore, since most people have reason to live lives that are not thoroughly centered on altruistic goals, and they should be helped when they encounter obstacles in their pursuit, they cannot be required to give up that pursuit in order to be beneficent to others. This principle is reasonable. But it is not obvious that it can be used to generate a fixed limit to the duty of beneficence. This is because the nature of any judgment about limits to beneficence must be comparative. A pursuit of a certain good may be requirement-grounding in certain contexts but not in others. In a context where A, B, and C are quite well off, it would not be wrong for $A$ (who is a musician) to build a collection of expensive musical instruments, and it might even be wrong for $B$ and $C$ not to help $\mathrm{A}$ build that collection. But in a different context in which $\mathrm{C}$ is starving, it would be wrong for B to help A build the collection when that money might instead go to feeding $C$. Since in this context A's pursuit is not requirement-grounding, it might not be absurd to ask $\mathrm{A}$ to make significant sacrifices (hampering their pursuit of musical sophistication) to help $\mathrm{C}$. The demandingness of (E) may then be quite extreme, and it is not clear that any fixed limit to those demands can be justifiable in a contractualist way.

Principle (E) seems objectionable from the point of view of fairness, however. The Conscientious Rich may complain that under (E) they are arbitrarily called to take up the slack left by the Careless Rich. This complaint seems to assume that principles of beneficence for nonideal contexts should not demand that conscientious agents do more than they would be required to do under ideal conditions. As Liam Murphy puts it, "a person need never sacrifice so much that he would end up less well off than he would be under full compliance from now on, but within that constraint he must do as much good as possible." ${ }^{10}$ A rough statement of the principle involved here might be the following:

\footnotetext{
${ }^{9}$ Garrett Cullity, The Moral Demands of Affluence (Oxford: Oxford University Press, 2004), p. 149.

${ }^{10}$ Liam Murphy, Moral Demands in Nonideal Theory (Oxford: Oxford University Press, 2000), pp. 86-87. For a full statement of Murphy's "collective principle of beneficence," see pp. 80-82.
} 
(F) Fair Shares Beneficence: Your basic positive duties of beneficence are to do your fair share in the collective efforts that would be reasonably optimal toward the eradication of destitution.

According to $(\mathrm{F})$, we must construe beneficence as a collective duty. The Rich have a collective duty to assist the Destitute. Each Rich will have to do her fair share, which would be identified on the basis of her level of resources when compared to other well-off people and as a function of a general calculation of what could be reasonably demanded from the Rich (as a group) to do to effectively contribute to the eradication of destitution. This principle may be quite demanding, but it cannot be unfairly so. The Conscientious Rich could invoke $(F)$ and reject $(E)$ when considering the extent of their basic positive duties in nonideal contexts. Would this rejection of $(E)$ on the basis of $(F)$ be reasonable?

Elizabeth Ashford has provided some compelling arguments to show that one cannot, on contractualist grounds, reject $(E)$ on the basis of $(F)$ when accounting for the basic positive duties of the Conscientious Rich toward the Destitute in nonideal contexts. ${ }^{11}$ Let me mention two of them. First, the Conscientious Rich cannot justify to the Destitute the choice of (F) over (E). Imagine that Rich A and Rich B have been assigned the collective duty to assist two Malawians in need of AIDS treatment for a year. Assuming that $A$ and $B$ have the same available resources, imagine that A's and B's fair shares would be $\$ 365$ each. Now assume that A is a Careless Rich who will not contribute her own fair share, whereas B is a Conscientious Rich who will. According to $(F)$, it would not be wrong for $\mathrm{B}$ to assist one of the Malawians while letting the other die. Could B justify her own decision not to contribute the extra $\$ 365$ that A failed to contribute to the dying Malawian? It seems that given the urgency of the situation, the Malawian can reasonably demand that B contribute the extra $\$ 365$. (E), not $(F)$, seems the least rejectable principle here. The collective failure of the rich as a group does not justify an absence of remedial duties of individual beneficence on the part of conscientious individuals. Second, even if fairness is taken to be the salient moral consideration here, one can say that the most serious unfairness in this context is for Malawians to have been born in conditions of destitution while most of the rich (including B) have been born in conditions of affluence. It would be unfair to let the natural lottery dictate that the Malawians face avoidable death while any of the Rich can live a luxurious life. ${ }^{12}$

A possible reply to these arguments is to say that they mobilize im-

${ }^{11}$ Ashford, "The Demandingness of Scanlon's Contractualism," pp. 289-92.

${ }^{12}$ The intuitive idea here is that it is unfair to let nonchosen circumstances determine people's dramatically unequal access to basic goods (such as subsistence) when this could be avoided through social action. 
portant moral concerns, but do not really affect (F). Murphy says, for example, that "our strong negative reaction to failures of rescue is based not so much on a sense that the agent acted terribly wrongly but on a sense that his emotional indifference to the victim's plight shows him to have an appalling character." 13 If Rich B chooses not to assist the extra Malawian we should not say that B did something wrong, but rather that B's character is morally reproachable. This seems to me to be a mistake. Why do we find B's character reproachable? The obvious answer is that what makes B's character reproachable is that it leads B to do what is wrong. We cannot consistently reproach B's character while condoning what makes that character reproachable.

\subsection{Shift to considerations of justice}

It seems that contractualist arguments would lead us to supplement (A) with $(\mathrm{E})$ and to drop $(\mathrm{F})$. Is this the end of the discussion? Not if there is an alternative to both $(\mathrm{E})$ and $(\mathrm{F})$ that no one could reasonably reject as an approach to poverty relief in our real, nonideal context. It is clear that even if (E) proves superior to (F), it occasions some moral worries that deserve our attention. A less demanding principle that also secures the claims of the Destitute would clearly be preferable. Even though the Destitute can reasonably reject $(F)$ when compared to $(E)$, the Conscientious Rich could reasonably reject or limit $(E)$ if there is an alternative principle that meets the Destitute's demands while accommodating at least some of their own concerns. I will now propose an account that incorporates the good points of $(E)$ and $(F)$ while avoiding their shortcomings. I take my cue from a remark made by Ashford in her critical discussion of (F). She suggests that the Conscientious Rich could say that "a principle that compels compliance with an equitable distribution of the burdens of giving aid, through a system of state taxation to fund aid to poor countries, cannot be reasonably rejected." ${ }^{14}$ Such a principle would, in securing the compliance of the Careless Rich, both satisfy the claims of the Destitute and the reasonable reservations about fairness advanced by the Conscientious Rich. It would, moreover, increase the efficiency of the aid effort. In what follows I will further develop this remark into a more detailed framework.

I suggest that we introduce a distinction between basic positive duties

\footnotetext{
${ }^{13}$ Murphy, Moral Demands in Nonideal Theory, p. 133.

${ }^{14}$ Ashford, "The Demandingness of Scanlon's Contractualism," p. 291. For Ashford's own account of duties correlative to socioeconomic human rights, see "The Duties Imposed by the Human Right to Basic Necessities," in Thomas Pogge (ed.), Freedom from Poverty as a Human Right: Who Owes What to the Very Poor? (Oxford: Oxford University Press, 2007).
} 
of beneficence and basic positive duties of justice. The latter, unlike the former, are to be seen as involving institutional articulation and coercive enforcement securing compliance. In what follows I will propose a contractualist approach to seeing basic positive duties of poverty relief as being primarily duties of justice. I do not say that they are only duties of justice, but that they are primarily so. Certainly when justice fails we have back-up duties of beneficence (most likely framed by (E)). But given the arguments I will present, it is a mistake to focus on informal duties of beneficence when an institutional framework of justice is more reasonable. The primary duties of the Rich are to uphold that institutional framework where it exists, and to create it when it does not exist. The argument that follows involves three moves. The first two briefly recount arguments that are already in circulation, whereas the third develops in some detail a contractualist account of basic positive duties of justice. The first move identifies the object of basic positive duties of justice of poverty relief as securing certain basic socioeconomic human rights. The second move recalls some standing facts about radical global inequality that make serious consideration of basic positive duties of justice feasible and urgent. The third move, finally, provides three grounds of consideration that make it reasonable, on contractualist grounds, to focus on institutional and coercive schemes rather than on informal individual demands of beneficence.

(1) If there is anything that no one could reasonably reject, this must include principles protecting basic human rights. ${ }^{15}$ We can plausibly see human rights as having at least two central features. The first is that they range over certain goods, access to which is a necessary condition for living a minimally decent life in any social context. Nutritious food, housing, health care, and education are some of the objects of such rights. A second central feature of human rights is that they function as normative grounds for shaping national and international institutions by setting basic negative and positive constraints. It follows that basic socioeconomic rights must be a decisive part of any plausible conception of global justice. ${ }^{16}$

${ }^{15}$ Notice that I am not feeding a list of rights into the contractualist procedure (which would be question-begging), but saying that such a list would be an output of contractualist reasoning. We can certainly see the basic interests protected by human rights as providing powerful generic reasons. Scanlon himself sees human rights as constraining institutions to attend to the satisfaction of people's basic interests. See T.M. Scanlon, "Human Rights as a Neutral Concern," in The Difficulty of Tolerance (Cambridge: Cambridge University Press, 2003), pp. 113-23.

${ }^{16}$ Consider Article 28 of the Universal Declaration of Human Rights: "Everyone is entitled to a social and international order in which the rights and freedoms set forth in this Declaration [which, in Articles 22-26, include socioeconomic rights] can be fully realized." Ian Brownlie and Guy S. Goodwin-Gill (eds.), Basic Documents on Human 
(2) The institutional protection of human rights becomes particularly relevant and urgent when their fulfillment is not, but can feasibly be, secured. This is the case not only with civil and political rights, but also with socioeconomic ones. Facts of radical inequality in our current world show that (a) more than a billion people do not have secure access to the objects of their socioeconomic rights; and (b) the world's Rich can fund the policies the Destitute need to avoid extreme poverty by merely sacrificing a very modest part of their aggregate income. ${ }^{17}$

(3) A natural question is what specific normative responsibilities result from universal norms stating human rights. Who should do what for whom? Some correlative duties for institutions and individuals are easy to identify. It is obvious that if there is a universal right against torture, then all institutions and individuals have the universal negative duty not to engage in or support practices of torture. It is less clear what the positive duties correlative to socioeconomic rights are (I will return to negative duties in section 4.1). ${ }^{18} \mathrm{~A}$ contractualist approach is distinctively helpful in this respect in at least two ways. First, since it is not only focused on the claims of recipients but also on those of agents, it potentially avoids the common danger of merely stating human rights without illuminating the correlative duties linked to them. Second, since contractualist justification is essentially comparative, demanding that our choice of principles be grounded on their being less reasonably rejectable than the alternatives, it helps us to decide between competing approaches by

Rights, 5th ed. (Oxford: Oxford University Press, 2006), p. 28. Many authors have made compelling cases for seeing basic socioeconomic rights as human rights. See James Nickel, "Poverty and Rights," The Philosophical Quarterly 55 (2005): 385-402; Thomas Pogge, World Poverty and Human Rights (Cambridge: Polity, 2002); and Henry Shue, Basic Rights, 2nd ed. (Princeton: Princeton University Press, 1996). For a systematic account of the constitutional articulation of socioeconomic rights and their juridical implementation, see Cécile Fabre, Social Rights Under the Constitution (Oxford: Oxford University Press, 2000). On emerging international mechanisms of justiciability, see Polly Vizard, Poverty and Human Rights (Oxford: Oxford University Press, 2006), chap. 5.

${ }^{17}$ There is some debate about the exact extent of severe global poverty. If one uses the World Bank's $\$ 1$ per day basis, then there were (as of 2001) approximately 1,092.7 million people living in extreme poverty, whereas if one uses the more accurate $\$ 2$ per day indicator, then the number goes up (as of 2001) to 2,735 million. Pogge forcefully argues that the second indicator (though not unproblematic) is better than the first, while also noting that the resources needed to eradicate global poverty (if used properly) amount to only about 1.2 percent of the aggregate income of the world's rich. See Pogge, World Poverty and Human Rights, and "The First UN Millennium Development Goal: A Cause for Celebration?" Journal of Human Development 5 (2004): 377-97. Regarding global inequality, data from 2001 show that the richest 20 percent captured 82.7 percent of the world's income, whereas the poorest 20 percent got only 1.4 percent. See David Held, Global Covenant (Cambridge: Polity, 2004), pp. 34-37.

${ }^{18}$ This problem is forcefully discussed by Onora O'Neill in Bounds of Justice (Cambridge: Cambridge University Press, 2000), chap. 7. 
paying serious attention to their relative advantages.

The best development of an account of basic positive duties of poverty relief must shift from considerations of beneficence to considerations of justice. The latter involves at least two important features: (a) a primary focus on institutional frameworks and (b) a readiness to introduce coercive enforcement to secure compliance with normative requirements. Pursuant to (a), we avoid a common picture of assistance in which individual agents have, in isolation from each other, a general imperfect duty to assist all those in need that they must choose, at their discretion, how to discharge. We seek, instead, an institutionally articulated picture in which resourceful individuals acquire different clearly specified obligations that, together, constitute a scheme of collective action geared to the eradication of destitution. Regarding (b), we entertain the introduction of legal mechanisms securing compliance, by clearly delineating penalties for those who do not comply with the scheme envisioned in (a).

It is certainly beyond the scope of this paper to develop a full account of the best scheme of responsibilities of justice regarding poverty relief. ${ }^{19}$ My philosophical goal is, instead, to provide a clear contractualist rationale for shifting our priorities from informal beneficence to institutional justice. The approach proposed here says that a reasonable construal of basic positive duties leads to the following general principle:

(G) Scheme of Justice: Your basic positive duties of justice are to do your fair share in the fulfillment of the coercively enforceable collective institutional scheme that would be reasonably optimal toward the eradication of destitution.

According to the view leading to (G), we have a duty to support and act in accordance with just institutions of poverty relief when they exist, and help to create them when they do not. In what follows, I will characterize the responsibilities of individuals under $(G)$ when an institutionalized scheme is in place. I will turn to the duty to help create some such scheme in section 4.3 below.

Two things must be noted to clarify the content of this principle. First, consider its similarities to and differences from $(F)$. Like $(F),(G)$ does not demand from people that they do more, though it does demand that they do no less, than their fair share to fulfill a collective basic positive duty of

\footnotetext{
${ }^{19}$ For an excellent collection of recent contributions to the emerging debate on the allocation of normative responsibilities correlative to socioeconomic human rights see Andrew Kuper (ed.), Global Responsibilities: Who Must Deliver on Human Rights? (New York: Routledge, 2005). The emphasis on institutional articulation and coercive enforcement was pioneered by Henry Shue. See his Basic Rights, chap. 5, and "Mediating Duties," Ethics 98 (1988): 687-704.
} 
poverty relief. However, unlike $(F),(G)$ presents this collective duty as a duty of justice, not beneficence. This difference has two consequences. The first is that it involves a concern for securing compliance by coercive mechanisms. The second is that $(G)$, unlike $(F)$, does not deny that there may be back-up duties of beneficence that go beyond doing one's fair share.

Second, consider (G)'s reference to the idea of a "reasonably optimal" collective institutional scheme. A collective scheme of poverty relief is reasonably optimal when it is the best at promoting the eradication of destitution without introducing unreasonable burdens to the duty-bearers (i.e., the Rich) and without disrespecting recipients (i.e., the Destitute). A collective scheme may be optimal but not reasonably so. It might, for example, force the Rich to engage in slave labor, or give them no democratic say on the design of the policies scheduling their contributions. Or it might, for example, fail to empower the Destitute by seeing them as mere passive recipients of aid instead of assisting them in the development of their own autonomous agency. The contractualist approach relies on a substantive normative view of persons as "reason-assessing, selfgoverning creatures" (WWO 106; see also 183). ${ }^{20}$ We can interpret this as having the implication that your assistance to others should cater to their autonomous functioning. Those you help should, as much as possible, be actively involved in the practices through which their material conditions of agency are improved. They should be protagonists of their own amelioration. This has decisive implications for institutional structures and policies of aid. The procedure through which these are designed should, to the extent that this is possible, be democratically accountable to those to whom they apply. ${ }^{21}$ And the content of policies should also cater to

\footnotetext{
${ }^{20}$ For detailed discussion on the substantive underpinnings of Scanlon's contractualism, see Rahul Kumar, "Reasonable Reasons in Contractualist Moral Argument," Ethics 114 (2003): 6-37.

${ }^{2 !}$ I do not claim that the presence of democratic practices and institutions is a necessary condition for the duty to introduce policies of aid. Both rich and developing countries suffer from several forms of democratic deficit. Furthermore, some "burdened societies" (to use John Rawls's expression in The Law of Peoples (Cambridge, Mass.: Harvard University Press, 1999)) are very far from being democratic, but should not for that reason be left without economic assistance. Democratic institutions are, however, an important desideratum for a view of justice fueled by contractualism. On a speculative note, one can suggest that the introduction of practices of deliberative democracy might be a desirable way of translating the "system of co-deliberation" (WWO 268) advocated by contractualism into the political sphere. To the extent that this is feasible, it would serve two functions. First, there is the epistemic value of facilitating the elucidation of genuinely "generic reasons." Given the complexity and variety of human experience, we cannot expect individuals to reliably identify what is in the best interest of all by merely engaging in introspective reasoning. Actual discussion with others of the kind favored by deliberative democracy might help them to check their views about how others would
} 
their autonomous functioning. If policies of aid should bolster the independence rather than the dependence of the Destitute, then some of them will be more reasonable than others. It is certainly better to invest in education and economic infrastructure, or to introduce regimes of fair trade creating incentives for local production in poor countries, than to set up regular shipping of finished products or make assistance contingent upon the promotion of cultural practices that those on the receiving end do not favor. The Destitute could reasonably reject policies of aid that do not cater to their dignified agency but build instead relations of condescending patronage.

As I said above, it is not an objective of this paper to provide a full account of the allocation of specific responsibilities for poverty relief. But it is important to notice that, at a minimum, such an allocation involves a complex "division of labor" between different agents. These include national governments, their citizens, international organizations (such as the International Monetary Fund, the World Bank, and the World Trade Organization), transnational corporations, and Non-Governmental Organizations (such as Oxfam). Each of these agents may be allocated normative responsibilities depending, for example, on their capacity for having an impact on poverty relief, and their historical causal role in the generation of conditions of destitution. In general, the aim is to secure that the collective effort is reasonably optimal in the sense discussed in the previous paragraph. In the rest of this section I will provide some examples of allocation of responsibility to illustrate the central point that an approach to poverty relief based on $(\mathrm{G})$ is superior to beneficence approaches based on $(\mathrm{A}),(\mathrm{E})$ or $(\mathrm{F})$. I will focus on three clear advantages.

(a) Efficiency. There are at least three kinds of inefficiency, usually found in informal beneficence, that could be addressed by the introduction of coordinated institutional schemes. The first is underfunding for certain crucial policies. A clear example is research and development regarding drugs to cure and prevent tropical diseases. Direct research by governments or indirect policies setting up clear incentives for pharmaceutical companies (or a combination of both) could achieve decisive victories in preventing or stopping millions of deaths each year. ${ }^{22}$ This

react to alternative principles and thus to come closer to genuine agreements with them. Second, public deliberation has also an intrinsic value: giving people the opportunity to join as free and equal co-deliberators has the "symbolic" significance of recognizing their status as self-governing rational and reasonable agents to whom laws must be justified. Scanlon helpfully discusses the fact that giving certain choices to agents may have a "symbolic" value as well as an "instrumental" value (WWO 253). Agents do not only care about what choices are made, but also about who makes them. The latter, symbolic concern has to do with the importance for people to be recognized as competent, independent free agents.

${ }^{22}$ See Thomas Pogge, "Human Rights and Global Health: A Research Program," Metaphilosophy 36 (2005): 182-209. See also the "Montreal Statement on the Human 
would be more efficient than aiming at funding the purchase of drugs that may not yet exist or whose price is excessive. A second form of inefficiency results from overfunding. Informal beneficence is in many cases associated with support for "client" states and groups whom the donor deems useful economic or political allies. This results in too much money being channeled to assist some, while others are thoroughly neglected. A third problem is misplaced funding priorities. This is evident, for example, when it comes to natural disasters. Much money is channeled to attend to the harmful effects of earthquakes or tsunamis, but very little is destined to building technical infrastructure to predict their occurrence and respond to them early. In all these cases, institutional frameworks setting up clear targets, mechanisms for review and accountability, and optimal allocation of funds would secure more efficiency than a chaotic aggregation of haphazard acts of beneficence on the part of isolated donors. Both the Rich and the Destitute have reasons to support institutional coordination as opposed to the informal mechanisms envisioned by $(A)$ and $(E)$. The Destitute have reason to prefer schemes that are more likely to meet their needs, while the Rich have reason to support schemes that minimize costs by actually delivering on what they pursue. For the same reasons, both the Destitute and the Conscientious Rich have reason to support the coercive enforcement of these institutionally coordinated schemes.

(b) Fairness. If all (or most of) those who can reasonably contribute to poverty relief did so, then each of them would have to do very little. But in nonideal contexts, if we rely on principle $(\mathrm{E})$, the complaints of the Conscientious Rich against the Careless Rich will go unheard, and the former will have to shoulder the burdens avoided by the latter. This is unfair. Since $(G)$ demands the introduction of mechanisms securing compliance, it attends to this unfairness. Meeting $(G)$ will require, of course, political imagination and decisiveness in the enforcement of internationally coordinated strategies of poverty relief. These are largely missing today. Take, for example, Official Development Assistance (ODA) geared to meeting the UN Millennium Development Goals (which include halving extreme poverty by 2015). Only a few countries are fulfilling the target of 0.7 percent of GNP pledged. The U.S. (the biggest economy in the world) contributed (in 2005) only 0.22 percent. What are needed here are formal schemes securing compliance. Examples would be progressive taxation of the wealthy at national levels ${ }^{23}$ and international economic penalties to

Right to Essential Medicines," in Stephen Marks (ed.), Health and Human Rights: Basic International Documents, 2nd ed. (Cambridge, Mass.: Harvard University Press, 2006).

${ }^{23}$ Consider, for example, the following proposal by Jeffrey Sachs for the United States, which includes "a 5 percent income tax surcharge on incomes above $\$ 200,000$ directed toward the U.S. contribution to end global poverty, which in 2004 would yield 
those countries and transnational corporations that fail to meet explicitly delineated targets of contribution. I will return to this in section 4.3 below.

(c) Motivational considerations. In ideal cases, motivating reasons and normative reasons converge. The reasons for accepting a principle $\mathrm{P}$ (together with the Contractualist Ideal to act only in justifiable ways) also shape the desires of agents to whom $P$ applies, and moves them to act on $\mathrm{P} .{ }^{24}$ However, in nonideal cases, this link between justification and motivation is, in fact, severed. Some agents may recognize the validity of $P$ but fail to be moved to act on it because some factually (not normatively) stronger desires that are not in tune with $\mathbf{P}$ move them to act in a way that violates $P$. This is, as we saw, the case with the Careless Rich's failure to discharge their duties of beneficence. How are conscientious agents to respond to this kind of situation? There are, I think, two possible reasonable moves to make. The first is to introduce supplementary motivational incentives to get agents to decide to do what they already have moral reason to do. The introduction of taxation to fund fair poverty relief policies creates, for example, extra prudential reasons for agents to do what would be right for them to do. ${ }^{25}$ This is a crucial way in which $(G)$ is different from, and better than, $(F)$ and $(E)$. (G) creates supplementary motivational incentives (avoiding legal penalties) that would get the

around $\$ 40$ billion. That surcharge could be paid as a tax to support U.S governmental efforts, or it could be directed by the taxpayer to a qualifying charity or philanthropy that has registered programs in support of the Millennium Development Goals" (The End of Poverty, pp. 307-8). For information regarding the UN Development Goals, see http:// www.un.org/millenniumgoals/.

${ }^{24}$ See T.M. Scanlon, "Metaphysics and Morals," Proceedings and Addresses of the American Philosophical Association 77, no. 2 (November 2003), pp. 7-22. For an elucidation of the notions of "normative" and "motivating" reasons and an excellent discussion about the extent to which they may or may not converge, see Michael Smith, The Moral Problem (Oxford: Blackwell, 1994), chap. 5. See also the discussion on Scanlon's account of motivation in the special symposium on Scanlon's book in Social Theory and Practice 28, no. 2 (April 2002). See, in particular, Gary Watson, "Contractualism and the Boundaries of Morality: Remarks on Scanlon's What We Owe To Each Other," pp. 22141; and David Copp and David Sobel, "Desires, Motives, and Reasons: Scanlon's Rationalistic Moral Psychology," pp. 243-76.

${ }^{25}$ It may also facilitate agents to act on desires they already have. As Judith Lichtenberg shows, one of the explanations why people do not give more even when they want to is that they often succumb to a more powerful desire to "keep up with the Joneses" in the battle for positional goods (preferring, for example, to refrain from giving money to charity when their neighbors use the same amount to buy a startling new car). See Lichtenberg, "Absence and the Unfond Heart: Why People are Less Giving than They Might Be," in Deen K. Chatterjee (ed.), The Ethics of Assistance: Morality and the Distant Needy (Cambridge: Cambridge University Press, 2004), pp. 75-97. Taxation solves this problem by imposing uniform contributions on all competitors. These considerations also apply to market competition. For example, some CEOs would be happy to make their companies more environmentally responsible, but worry that if they do so unilaterally, they would be led to bankruptcy if competitors do not make the same costly adjustments. 
Careless Rich to do what is right. This move seems reasonable given the facts that the deaths of millions of Destitute, and unfairly heavy demands on the Conscientious Rich, would otherwise result.

The second move is to devise practices through which people's motivating reasons may become colored by their normative ones. Scanlon distinguishes between reasons in the normative sense and reasons in the operative sense (WWO 18-19). The latter are the reasons the agent takes to be valid, whereas the former are the reasons the agent should take to be valid. Scanlon rightly points out that reflective agents, to the extent that they proceed rationally, could not but seek those operative reasons that match normative reasons. But this does not imply that operative reasons that match normative reasons automatically become actually motivating reasons for an agent. This gap can partially be filled by the move mentioned in the previous paragraph. But this cannot be the end of the story.

We must, further, try to do two important things. First, we must make sure that in cases in which we mobilize motivating reasons whose content is not that of the normative ones (as is the case with the Careless Rich who pay the taxes because they want to avoid the penalties and not because they believe they ought to contribute to the eradication of destitution), we can still provide a normatively sound justification for doing so. And, second, we must not give up on the attempt to get agents to shape not only their operative reasons, but also their motivating reasons in terms of their normative ones. The first task can be secured by emphasizing the public nature of contractualist justification. ${ }^{26}$ Coercive laws can be publicly justified by making available to all those affected nonrejectable grounds for their introduction. Contractualism need not (like some forms of utilitarianism) generate a distinction between esoteric and exoteric reasons. The latter are the same as the former: a coercive scheme can and must be justified to agents on grounds that they could not reasonably reject, even if those are not the grounds they choose to act from. The second task is more complicated, and is one usually neglected by contractualists. It is not enough to assume that rational agents can act on the basis of the normative reasons that they have. We must also inquire about how they may be more or less ready to do so. This is why practices of public justification may need to be connected with the creation of a culture of "solidarity with strangers," in which those to whom we owe reasons and right conduct are also emotionally salient to us. Notice that the presence of this culture is not a need from the point of view

${ }^{26}$ The dimension of publicity in contractualist reasoning is illuminatingly explored by Samuel Freeman, "Moral Contractualism as a Foundation for Interpersonal Morality," in Dreier (ed.), Contemporary Debates in Moral Theory, pp. 57-76. 
of justification, but only from the point of view of motivation. Since we have independent normative reasons to assist distant others, we should see to it that we nourish our moral sensibility in such a way that those reasons gain traction in our habits, conduct, and institutions.

These issues regarding motivation certainly require further exploration. The general philosophical point underlying my discussion is, however, the following. Contractualist reasoning in nonideal contexts must take not only the point of view of the morally reflective agent (for whom justification and motivation converge) but also the point of view of the observer (who notices the extent to which justification and motivation in fact come apart in the psychological economy of acting persons). The challenge is to pay due attention to the second perspective without relinquishing the demands of the first. ${ }^{27}$ This is what the introduction of $(G)$ attempts to do in the case of poverty relief, and what insistence on informal beneficence seems largely to miss.

\section{Objections and Implications}

\subsection{Causal and normative responsibility}

An important principled complaint against seeing basic positive duties as duties of justice is the familiar libertarian objection. Libertarians appeal to the following principle:

(H) Justice as negative duties: Your duties of justice are only negative duties not to unduly harm others. You can only have positive duties of justice in a derivative way, as rectification for undue harm done. ${ }^{28}$

According to $(\mathrm{H})$, fundamental enforceable duties of justice can only be negative. It does make sense, for example, to institute coercive enforcement of laws banning physical aggression to innocent people. But we cannot enforce aid to the needy. Aid may be required as a matter of charity or informal beneficence, but not as a matter of justice. The only exception is when assisting others would be the appropriate way of compensating them for an undue harm done to them. For example, it makes sense to say that people have a negative duty of justice not to make others destitute. If this negative duty is violated, assistance would be justified as rectification. Thus, applied to the issue of poverty relief, the libertarian objection would amount to the following argument:

\footnotetext{
${ }^{27}$ In his account of motivation, in chapter 4 of $W W O$, Scanlon only considers the first perspective.

${ }^{28}$ Other routes to derived positive duties are to make promises and enter into contracts.
} 
Normative premise: Principle $(\mathrm{H})$ applied to the problem of destitution: $\left(\mathrm{H}^{*}\right)$ You have a negative duty of justice not to unduly harm others by making them destitute. You can only have positive duties of justice of poverty relief in a derivative way, as rectification for violating the negative duty referred to in the previous sentence.

Factual premise: The Rich have not been causally involved in bringing about the destitution of the Destitute.

Conclusion: The Rich do not have a positive duty of justice of poverty relief toward the Destitute. ${ }^{29}$

This argument has two serious problems: (1) it does not acknowledge the extent to which the Rich do have derivative positive duties of justice toward the Destitute; (2) it relies on an unacceptably narrow account of normative responsibility. ${ }^{30}$ Explaining each of these points will further elaborate the contractualist approach developed here.

(1) Derived basic positive duties of justice. The first problem with the libertarian argument is that its factual premise is false. It is hardly the case that the global Rich have not been systematically involved in unduly harming the global Destitute. Even if it were true that destitution in poor countries primarily results from their governments' inefficient and corrupt policies and their lack of encouragement of efficient economic practices, it would be a mistake to think that the world's Rich are not implicated. As Thomas Pogge's recent work forcefully shows, the global Rich have been using their overwhelming bargaining power to shape the international political and economic landscape in a way that makes it possible and desirable for elites in poor countries to act as they do. Two characteristics of that order are what Pogge calls the "international borrowing privilege" and the "international resource privilege" (under which authoritarian or corrupt elites in poor countries are internationally allowed, and even encouraged, to appropriate and sell the natural resources of the countries they rule, and contract public debt in their people's name, with devastating political and economic consequences). ${ }^{31}$ Moreover, we should not think that only governments, and not the members of the in-

${ }^{29}$ For a recent example of this line of argument, see Jan Narveson, "We Don't Owe Them a Thing! A Tough-Minded but Soft-Hearted View of Aid to the Faraway Needy," The Monist 86 (2003): 419-33; and "Welfare and Wealth: Poverty and Justice in Today's World," Journal of Ethics 8 (2004): 305-48. For a discussion of libertarianism, see Pablo Gilabert, "Basic Positive Duties of Justice and Narveson's Libertarian Challenge," The Southern Journal of Philosophy 44 (2006): 193-216.

${ }^{30} \mathrm{~A}$ third problem is that it fails to see that legal coercion can be authorized and monitored through democratic practices.

${ }^{31}$ Pogge, World Poverty and Human Rights, pp. 22-23, 112-16. 
ternational business community, are to blame. There is ample evidence that some sectors of the latter have supported harmful governments and policies in poor countries. ${ }^{32}$ In sum, exploitation and domination are common features of international relations, and destitution cannot be explained without paying attention to them.

(2) Nonderived basic positive duties of justice. Contractualist reasoning would certainly support views of enforceable duties of poverty relief as rectification for harm done. But it need not be limited to that. In fact, a contractualist case can be built for rejecting the normative premise of the libertarian argument. We can show that principle $\left(\mathrm{H}^{*}\right)$ could reasonably be rejected, and thus that the Rich also have nonderived basic positive duties of justice to assist the Destitute. To do this, we need to consider more closely the notion of responsibility. We can distinguish between normative and causal responsibility regarding the suffering of the Destitute. $A$ is causally responsible for the destitution of $B$ if $B$ 's destitution results from a causal process in which $\mathrm{A}$ has been involved. $\mathrm{A}$ is normatively responsible for relieving B's destitution if there is a principle $\mathrm{P}$ according to which it would be wrong for $A$ not to do so. Principle $\left(\mathrm{H}^{*}\right)$ assumes that for $\mathbf{P}$ to be an acceptable principle, it must include as one of its conditions that $A$ is causally responsible for B's destitution. Should we then abandon (G), which does not include this condition, and endorse $\left(\mathrm{H}^{*}\right)$, which includes it? Is it true that normative responsibility must track causal responsibility?

(G) generates schemes that impose costs on the Rich to benefit the Destitute. This imposition is coercively enforceable, for example by means of taxation. To see whether such an enforcement of basic positive duties is acceptable without having to rely on facts of causal responsibility, we need to compare the generic reasons involved. A defender of (G) would have to show that the generic reasons for rejecting $\left(\mathrm{H}^{*}\right)$ are stronger than the generic reasons for rejecting $(G)$. Is the interest of the Rich in not being taxed weightier than the interest of the Destitute in there being public institutions securing assistance to those in dire need? It seems fairly obvious, from an impartial perspective, that the concerns of the Destitute have more weight than those of the Rich. Of course, the kind of assistance required from the Rich cannot be unreasonable (for example involving slave labor). But $(\mathrm{G})$ recognizes that. What $(\mathrm{G})$ does not recognize is a sweeping entitlement not to be taxed to help fellow human beings in dire need. Given the empirical data discussed above, the global Rich can do their fair share to help eradicate the extreme poverty of the Destitute at a rather minimal cost to themselves. An enforceable

\footnotetext{
${ }^{32}$ See the recent "global corruption reports" by Transparency International (TI) at http:// www.globalcorruptionreport.org. The chairman of TI, Peter Eigen, is reported to claim that "a lot of the responsibility for corruption in the developing world has been with the Northern companies and Northern institutions" (The Guardian Weekly, April 1-7, 2004, p. 3).
} 
scheme securing this would partially curtail the economic liberty of the Rich (not allowing them to do whatever they want with their pretax income), but this is not a sufficient ground for rejecting a principle on whose observance the survival of millions of people depends.

Some libertarians might protest by invoking a construal of the contractual situation according to which no principle can be acceptable unless it proves mutually beneficial to all the parties involved. Since it is not clear that $(G)$ would benefit the Rich as well as the Destitute (as the Rich are much more likely to be on the giving rather than on the receiving side of the equation), it is not clear that the Rich could not reasonably reject $(\mathrm{G})$. But Scanlon rightly condemns mutual advantage contractarianism (WWO 180, 192-93, 207-8). There are cases in which you could not reasonably reject a principle even if you could rationally (in the instrumental sense of "rationally" that tracks personal advantage as the decisive factor) prefer an alternative one. When one reflects on whether to reject a principle, one must take into account the standpoints of all those concerned, considering how the principle would burden agents and benefit subjects. But in doing so one must "leav[e] aside the likelihood of one's actually falling in either of these two classes" (WWO 208). The Rich may find that they are worse off under $(G)$ than they would be under a principle like $\left(\mathrm{H}^{*}\right)$ allowing them not to contribute to the eradication of poverty in whose causal production they have not been involved. But this fact does not ground reasonable rejection of $(G)$, because the Destitute would be much more seriously worse off under the alternative principle than the Rich would be under $(G)$. A truly impartial, reasonable consideration of people's interests would support $(G)$. The positions of power and advantage from which people evaluate alternative principles should not be allowed to determine their judgment.

In a contractualist approach, claims of normative responsibility depend on substantive moral considerations. Scanlon helpfully distinguishes between claims about what we owe to each other (claims about normative responsibility) and claims about what actions can be causally attributed to certain agents ( $W W O 248,290$ ). It is important not to conflate these two kinds of claims. Their connection, if and when it exists, depends on substantive principles about the conditions under which the choices made by certain agents should be seen as bearing on the way their interactions with others ought to be morally framed. Claims regarding derived and nonderived positive duties are substantive claims about normative responsibility. Whereas the former are backward-looking, the latter are forward-looking. The former reach judgments about what individuals or groups owe to each other on the basis of what they did to each other, whereas the latter reach such judgments on the basis of what individuals or groups can do for each other. Given the weight of the generic 
reason all agents have to avoid destitution, and the relatively low cost at which the Rich could help eradicate it, it is implausible to say that basic positive duties of justice should only be seen as derivative ones. Perhaps claims about past harms can be cited to identify the primary bearers of basic positive duties. Other things being equal, if $\mathrm{A}$ and $\mathrm{B}$ are Rich and $\mathrm{C}$ is Destitute, and A is causally responsible for C's destitution whereas B is not, then A should be the first to do something to assist $\mathrm{C}$. However, it makes sense to say that $B$ may still have to do something even if he has not been involved in causing C's destitution. (For example, if A is not able to do all that is needed to help eradicate C's destitution without B's assistance, then it seems wrong to say that $B$ is not required to do anything.)

I suggest, thus, that views of normative responsibility based on claims about causal responsibility be understood as establishing sufficient or priority conditions, but not necessary conditions, for basic assistance. This suggestion would apply to Christian Barry's recent proposal of the "contribution principle," according to which "agents are responsible for addressing acute deprivations when they have contributed, or are contributing, to bringing them about." ${ }^{33}$ Despite what this principle says, some people may be normatively responsible for addressing acute deprivations even if they have not contributed, or are not contributing, to bringing them about. Thus this principle would be implausible if it refers to necessary as well as sufficient conditions for poverty relief. The contribution principle might instead be seen as presenting, at best, an order of priority rather than an absolute clause: we should focus first, though not exclusively, on the normative responsibilities of those who have engaged in harmful activities. ${ }^{34}$

${ }^{33}$ Christian Barry, "Applying the Contribution Principle," Metaphilosophy 36 (2005): 210-27, p. 211. For a useful discussion of different conceptions of normative responsibility, see David Miller, "Distributing Responsibilities," in Kuper (ed.), Global Responsibilities, pp. 95-115.

${ }^{34}$ We should also notice that not all backward-looking views are based on claims about harm. Some of them may track claims about merit, which may hold in the absence of any previous harmful activities. For example, it may be argued that A should prioritize assistance to $B$ over assistance to $C$ because C's condition of destitution has resulted from C's choices whereas B's condition of destitution has come about independently of B's choices. Furthermore, it may be argued that if $A$ and $D$ are wealthy and can help B or C, if A's wealth is the result of A's choices whereas D's wealth has come about independently of D's choices, then we should give priority to D over A in the allocation of duties to aid. These considerations seem intuitively appealing. However, given the urgency of the claims of the Destitute and the low costs that the Rich would have to shoulder to assist them, their role should be, at best, to provide some guidelines regarding how to allocate specific basic positive duties to the Rich, not regarding whether the Rich as a group have the normative responsibility to uphold a scheme of poverty relief. 


\subsection{Global scope}

The "tightening" of contractualist reasoning has led us to viewing $(\mathrm{G})$ as a global principle of justice. This view may be the target of the objection that the scope of $(\mathrm{G})$ cannot be global because there is no global state. This objection relies on the claim that principles of distributive justice are only triggered within the boundaries of nation-states. Support for this claim might be found in a recent article by Thomas Nagel. ${ }^{35}$ Nagel argues that positive rights regarding distributive justice only hold for relations between people who share a centralized political community, a nation-state, because of the unique way in which its citizens are asked to make and to follow the laws under which they live. Since there is no global state, global basic positive duties (which cater to a subset of the group of positive distributive rights) can at best be humanitarian duties of rescue, not enforceable duties of justice. I think that this view is mistaken. Even if it were true that in the absence of a centralized global state we cannot introduce fully egalitarian principles of global equality of opportunity, or global versions of Rawls's Difference Principle, we may still find sufficient grounds for articulating robust principles of poverty relief that are not merely humanitarian demands, but stringent and enforceable duties of justice. It is possible to carve out conceptual space for a domain of global justice focused on basic socioeconomic human rights, which are different from weaker humanitarian demands and from stronger schemes of domestic justice. ${ }^{36}$ This can be done in at least two ways.

First, we can refer to facts of globalization that have already been generating diverse forms of supranational interdependence, including dense economic and political international practices and institutions. For

${ }^{35}$ Thomas Nagel, "The Problem of Global Justice," Philosophy and Public Affairs 33 (2005): 113-47.

${ }^{36}$ I am not saying that we should not accept global versions of the principles of equality of opportunity and the Difference Principle. I simply put this issue aside, and, focusing on basic rights of poverty relief, I claim that they are more than merely weak humanitarian claims. Nagel does recognize that there are some universal demands associated with human rights, noticing that any Kantian moral theory (including Scanlon's contractualism) would support them ("The Problem of Global Justice," p. 131). Nagel mentions "negative rights" against "violence, enslavement, and coercion" (ibid.). He also refers to a universal "duty of rescue toward people in dire straights" (p. 132). What Nagel wants to do is to draw a clear line between these minimal duties of universal morality and more demanding ones connected with egalitarian distributive justice. I do not think that this view accommodates the robust account of basic positive duties of justice demanded in this paper. First, these duties may be more demanding than humanitarian duties of occasional and easy rescue. The target of $(G)$ is the eradication of severe poverty. Second, $(G)$ involves enforceable schemes. These would contain much more comprehensive institutions and mechanisms than those currently provided by charity NGOs and the World Bank (the two examples mentioned by Nagel). 
example, the rulings of the World Trade Organization and the International Monetary Fund have pervasive effects on the well-being of people across the world. The demands of "structural adjustment" by the IMF contributed to increasing levels of poverty in Latin America, while the failure of the WTO to bring down tariffs on imports by rich countries arguably prevented one of the most efficient ways of combating destitution in poor countries. These facts of globalization seem sufficient for grounding the international articulation of basic positive duties of justice and the call for reforms in the organization of international institutions so as to make them democratically accountable to those affected by them. ${ }^{37}$ A global political community of sorts is already in the process of being created. For example, a growing body of international law has been generated since the UN was established. Substantively sound and procedurally legitimate ways of articulating, expanding, and implementing this body of law can be further developed. Nation-states need not be obliterated, but their sovereignty might reasonably be seen as conditional upon their compliance with international regulations geared to securing the fulfillment of basic human rights, including socioeconomic ones. ${ }^{38}$

Alternatively, we can invoke a cosmopolitan perspective according to which basic positive duties are not merely humanitarian duties but also duties of global justice simply because some human beings can, at reasonable cost to themselves, assist other human beings in need. According to the cosmopolitan view, normative responsibilities of basic justice are not conditional upon common membership in an already existing political community. Democratic structures of domestic and global governance may then be seen not as a precondition for the existence of basic positive duties of justice, but as a way of securing their fair and efficient institutional articulation and discharge.

It seems to me that contractualist reasoning can support both of these views when compared to the narrow, nation-state-centered approach. Should we choose one of them? The strength of the first view is that it relies on the obvious facts of increasing political, economic (and, we should add, military) interdependence. The second view seems by contrast utopian, not anchored in actual historical processes. The strength of the second view is, on the other hand, its moral simplicity and directed-

${ }^{37}$ This is the position defended in Joshua Cohen and Charles Sabel, "Extra Rempublicam Nulla Justitia?" Philosophy and Public Affairs 34 (2006): 147-75. The facts regarding global harms discussed in section 4.1 should also be taken into account here.

${ }^{38}$ For a discussion of the possibility of "multilevel citizenship" (i.e., of people's participation in interlocking political communities comprising national, international, and transnational institutions), see Held, Global Covenant. Held argues that multilevel citizenship does not amount to a much-feared unaccountable "world state." A principle of subsidiarity can be retained, securing a relative level of autonomy for nation-states while also expanding the power of supranational institutions dealing with issues of global concern. 
ness. It says, upfront, that we have enforceable duties of justice to assist human beings in need (regardless of their national membership) whenever we can do so at reasonable cost to ourselves. Another important advantage of the cosmopolitan view is that it can prevent the following possible response to the claim that $(G)$ yields global duties of justice. Some people in rich countries might decide to interrupt the ongoing process of globalization, retreat into their own nation-states, and invoke the first view to say that they do not have global basic positive duties of justice because no robust associative facts regarding their relation to the rest of the world remain. This response would not be acceptable if we hold the cosmopolitan view, according to which the retreating Rich would continue to have basic positive duties of justice if they can still do something to alleviate the suffering of the Destitute. This consideration seems to support the second view when compared to the first. But in fact both views can be combined, provided that the first is seen as presenting sufficient, but not necessary, conditions for global normative responsibility.

The previous paragraph proceeds on the basis of the assumption that the scope of contractualist reasoning about political morality is always already universal; that the extent to which structures of governance are inclusive or exclusive should be justifiable to members and nonmembers alike. This assumption may seem arbitrary. But so would the opposite assumption, which uncritically grants the outcomes of the natural lottery that determines that some people are born in rich political communities while others are destined to poor ones. Surely the former assumption is stronger, on grounds of fairness, than the latter.

\subsection{Institutional reform in nonideal circumstances}

We have pursued a "tightening" of contractualist reasoning regarding principles of poverty relief. The best such principles would introduce, following the general guidelines of $(\mathrm{G})$, collective and enforceable schemes of assistance rather than individual and informal duties of beneficence. But we must consider an obvious and important challenge. Institutional structures implementing $(G)$ are largely missing. It is thus not clear what the responsibilities of national governments, international institutions, and individuals are. The second part of the view leading to $(G)$ says that just institutions implementing $(G)$ should be created when they do not exist. I will thus conclude this paper by introducing some tentative remarks on the difficult issue of institutional reform under nonideal circumstances.

(1) Transitional standpoint. First, we should properly identify the context of our discussion. It seems clear that we are neither under conditions in which $(G)$ is fully implemented nor in a Hobbesian state of nature where no normative and institutional frameworks whatsoever exist. 
Our standpoint is a transitional one. We can identify trends toward the identification and implementation of schemes of international justice. Think about human rights law. There have been numerous international treaties and conventions, and many of their demands have been enshrined in national constitutions and pursued by international institutional bodies and civil society. We certainly lack sufficient mechanisms for articulating and enforcing the implementation of basic socioeconomic human rights, but we are not facing a situation in which their great importance is not recognized or where no attempts are being made to secure them. For example, the governments of developed countries have pledged 0.7 of their GDP to halve world poverty by 2015 . They have pledged to make the Doha round of the WTO a "development round." Of course, they are not fully delivering on these commitments. But now that these commitments have been made, the burden is on them to show why they are not delivering, not on others to say why they should.

A transitional standpoint involves a dynamic approach. It is guided by both ideal-theoretical and feasibility considerations. In the case of poverty relief, an ideal-theoretical state would be one in which national and international institutions are in place securing the full implementation of what (G) demands. ${ }^{39}$ Since we are not there yet, we must ask ourselves what feasible steps can be taken to approach that state. We may then identify different paths of reform, and entertain trajectories of reform passing through successive thresholds of feasibility. Reforms that are not feasible now may become feasible later on as a result of successfully introducing other feasible reforms. This means that for any given context, we must ask what paths of reform are reasonable and feasible, and choose those that are likely to lead to generating conditions of feasibility for further reasonable improvements.

(2) Multiple institutional paths. I mentioned tax and transfer schemes by means of which the governments of developed countries can get their Rich to assist the Destitute. There are different ways in which these schemes can be conceived. An important consideration is whether their recipients are governments or individuals and associations. It seems reasonable to say that when political institutions in a developing country are robust and democratically accountable, they should be the recipients of aid. When developing countries are ruled by despotic or corrupt elites, aid

\footnotetext{
${ }^{39}$ I am not saying that this would be the final ideal-theoretical state regarding global justice. The latter might well be more demanding, including schemes of global equality of opportunity and a global version of Rawls's Difference Principle. For a defense of such a stronger picture, see Kok-Chor Tan, Justice without Borders (Cambridge: Cambridge University Press, 2004). As I said in section 4.2, I am putting this aside. An ongoing scheme securing poverty relief is an aspect of global justice even if further trajectories of reform should eventually go deeper.
} 
may be directed instead to sectors of civil society that are more likely to pursue reform of political institutions or economically sound practices. ${ }^{40}$

Direct aid is not the only reasonable mechanism. Other reasonable institutional reforms are conceivable. An important example would concern the rules of international trade. In fact, "rich countries have cost poor countries three times more in trade restrictions than they give in total development aid." and "fair trade" and the pledge to make the Doha round a "development round," developed countries have used their overwhelming bargaining power in the WTO to get developing countries to open their economy to developed countries' manufactured products and services without reciprocally opening their own economy to developing countries' agricultural products. A sustainable scheme of poverty relief should certainly involve changing the rules of trade in order to make them fairer. ${ }^{42}$

Multiple paths of reform can then be pursued. A difficult problem is to make them enforceable. The final target of reforms might be an international body able to oversee and enforce implementations of $(G)$. A recent proposal in this direction is the establishment (within the UN) of an Economic and Social Security Council to coordinate poverty reduction and global development policies. ${ }^{43}$ If (and while) this is not immediately feasible, other steps can be taken. The World Bank, the IMF and the WTO can be made to work toward poverty relief. This can be brought about through changes in their procedures of decision-making and their outcomes. Two recent proposals by Stiglitz seeking to overcome the "democratic deficit" of these international organizations are worth immediate

${ }^{40}$ On the importance of targeting institution-building, see Mathias Risse, "What We Owe to the Global Poor," The Journal of Ethics 9 (2005): 81-117. I agree with William Easterly that many aid policies have been ineffective. It is true that "sixty years of countless reform schemes to aid agencies and dozens of different plans, and $\$ 2.3$ trillion later, the aid industry is still failing to reach the beautiful goal." The White Man's Burden (New York: Penguin, 2006), p. 11. But this sweeping claim may obscure important facts. See on this Branko Milanovic, "Reply to Easterly: Thought-Provoking and Misleading," Cato Unbound, April 5, 2006. $\$ 2.3$ trillion is not so much money given the time period considered, and the bulk of that money was actually not used in policies targeting development and poverty alleviation. As we saw in previous sections, developed countries have also simultaneously pursued other policies that effectively thwarted development and fair institution-building.

${ }^{41}$ Joseph Stiglitz, Making Globalization Work (New York: Norton, 2006), p. 78. In chapter 3, Stiglitz advances several feasible proposals for making trade fairer.

${ }^{42}$ For example, developed countries should allow developing countries to protect their nascent industries, and to export their agricultural products.

${ }^{43}$ See Frances Stewart and Sam Daws, "An Economic and Social Security Council at the United Nations," at http://econpapers.repec.org/paper/qehqehwps/qehwps68.htm. See also the UN Press Release at http://www.un.org/News/Press/docs/2003/gaef3043.doc. htm; Peter Singer, One World (New Haven: Yale University Press, 2002), p. 200; and Held, Global Covenant, p. 164. 
consideration. First, "strong freedom of information acts" should be introduced to make sure that their proceedings are open to public scrutiny. Second, steps should be taken to enhance "the ability of developing countries to participate meaningfully in decision making, by providing them with assistance in assessing the impact on them of proposed changes." ${ }^{, 44}$ More long-term strategies targeting the reform of international structures of governance (reducing the current imbalance in bargaining power and strengthening democratic accountability) can thereby be empowered. Informed political agents are more likely to choose political reforms that actually take their needs into account. Furthermore, the collective action of developing countries may have real consequences. One of the reasons why the unfair trade schemes pushed by developed countries at the Doha round have not gone through is that many developing countries are starting to negotiate as a block. This may eventually facilitate deeper and more permanent changes in the structures of global governance.

(3) Motivation for reform. A natural question is whether we can expect citizens of developed countries to accept being taxed to support poverty relief schemes, or to support trade regimes that reduce some of the advantages they have become accustomed to. Is it really feasible to pursue these immediate institutional reforms? It seems to me that a skeptical answer to this question is not warranted. Citizens of wealthy countries have both moral and prudential reasons to favor institutional reforms implementing $(\mathrm{G})$. The moral reasons should be obvious from our discussion so far. Even if moral reasons are not always operative or dominant, they are by no means impotent. There is in fact a growing consensus on the urgency of global issues among citizens in wealthy societies. Consider the example of the threat posed by global warming. Even when many politicians in the United States and the lobbying corporations that determine much of their campaign finances neglect their duty to support schemes for pollution control, the pressure by conscientious citizens is gaining strength (and is already reaching fruition at the local and state level, as is the case with the recent environmental controls introduced by California). Similar developments can be expected with respect to poverty relief policies.

Citizens of wealthy societies also have prudential reasons to support policies implementing $(\mathrm{G})$. These may include the fear of growing illegal immigration, terrorism, diseases, and international insecurity, and the prospect for potential economic gains to be expected as the Destitute become producers of goods the Rich can consume and consumers of goods the Rich can sell to them. As Kant argued in "Perpetual Peace," prudential reasons may converge with moral reasons, and sometimes the former

\footnotetext{
${ }^{44}$ Stiglitz, Making Globalization Work, p. 253.
} 
may be particularly efficient in generating an international order the latter already demand. ${ }^{45}$ Global justice is not a zero-sum game.

(4) Superiority with respect to informal beneficence. Another worry might be that it is not clear that the conscientious Rich should focus on institutional reforms rather than on informal beneficence because the prospects of the former are uncertain whereas contributing to beneficent NGOs has a clear and immediate impact. This worry is not, I think, warranted. First, as we saw, informal beneficence is far from being an efficient mechanism, and thus its prospects regarding poverty relief are quite uncertain. Second, the paths of institutional reform are not so uncertain. I mentioned several proposals for immediate feasible reforms and some proposals for long-term reforms. The uncertainty surrounding institutional reforms will decrease as more research and action is devoted to them. It is in this respect relevant to note that Oxfam, one of the most respected NGOs focused on poverty relief, itself devotes significant resources to campaigns pressuring national and international institutions to introduce coordinated institutional reforms. ${ }^{46}$ Finally, the institutional approach demanded by $(G)$ is more sustainable, as it focuses on the creation of a background structure of ongoing institutions rather than on occasional acts of rescue. It thus addresses the need to generate compliance preventing the common problems of "free riding" and "assistance fatigue."

I conclude that in the absence of just institutions, the first priority should be to create them rather than to relapse into beneficence. The reason is that just institutions, as we saw, are more likely than informal assistance to secure the fair discharge of basic positive duties of poverty relief. Back-up duties of beneficence may be seen as functioning in extreme circumstances in which just institutions neither exist nor are likely to be created, but it is hard to claim that these circumstances really hold with respect to poverty relief. In fact, to prioritize informal beneficence when just institutions can be created is to fail to take seriously the demands of poverty relief. An analogy between the global and the domestic contexts would, I think, make this clear. Before the introduction of the welfare state in industrialized capitalist societies, conscientious agents had the choice of devoting their efforts to informal beneficence or to institutional reform. No one who recognizes the importance of poverty relief would deny that it was a good thing that these agents favored the second option. The same can be said about our current global situation. Institutional reforms are, as we saw, feasible. Thus, devoting our efforts

\footnotetext{
${ }^{45}$ Immanuel Kant, "Toward Perpetual Peace," in The Cambridge Edition of the Works of Immanuel Kant: Practical Philosophy, ed. Mary Gregor (Cambridge: Cambridge University Press, 1996), pp. 311-51.

${ }^{46}$ An example is Oxfam's "Make Trade Fair" campaign. See http://www.oxfam.org/ en/programs/campaigns/maketradefair.
} 
to their creation should have priority.

(5) Extent of demandingness of the duty to contribute to institutional reform. I have argued that in the absence of just institutions, the first priority should be to create them rather than to relapse into informal beneficence. But how strong is the duty to contribute to institutional reform $?^{47}$ If $(G)$ is implemented, then the problems of beneficence under nonideal circumstances would largely be overcome. But if the institutions implementing $(G)$ are not in place, then the duty to help create them is likely to face problems similar to those facing beneficence. I will thus conclude this paper by doing two things. First, I will compare the demandingness of the duty to engage in institutional reform to implement $(\mathrm{G})$ and the demandingness of $(E)$ and $(F)$. Second, I will address concerns about the feasibility of the former in view of its possible collision with special responsibilities. In both cases, I will focus on showing that the shift from informal beneficence to institutional justice is reasonable, and that a transitional standpoint helps us to see why and how this is so.

With respect to the first issue, we should start by saying that a duty to engage in institutional reform should not be as weak as $(F)$. $(F)$ is implausible with respect to informal beneficence, as we saw. But it is also implausible with respect to the duty to contribute to institutional reform. Just as it would be wrong to let a second child drown because you saved one and the other person who can help is not ready to do her fair share and save the other, so would it be wrong for a conscientious Rich not to do more than her fair share to promote institutional reform because another Rich is not ready to do her fair share.

A natural question then is whether the duty to engage in institutional reform might be as demanding as (E). My answer to this question is that even if initially this is the case, in time it is not likely to be so. A duty of

\footnotetext{
${ }^{47} \mathrm{I}$ am assuming that a conception of justice must include something like what Rawls calls a "natural duty of justice" to not only support existing just institutions but also to contribute to their creation when they do not exist. Rawls's discussion of the second part of the natural duty is, however, very brief, and does not include a precise account of the extent of its demandingness. Rawls says that the natural duty of justice "constrains us to further just arrangements not yet established, at least when this can be done without too much cost to ourselves." Rawls, $A$ Theory of Justice, rev. ed. (Cambridge, Mass: Harvard University Press, 1999), p. 99; see also pp. 293-94. This formulation does not identify a cut-off point. It also does not address the issue of the scope of the duty. An important objection in this respect is that it cannot explain why agents owe allegiance to the institutions of their own country as opposed to those of other countries. See A. John Simmons, Moral Principles and Political Obligations (Princeton: Princeton University Press, 1979), chap. VI. For a powerful response, see Christopher Heath Wellman, "Political Obligation and the Particularity Requirement," Legal Theory 10 (2004): 97-115. My approach, like Wellman's, starts with a general moral account of positive duties, and proceeds to identify their institutional articulation on the basis of considerations of fairness and efficiency. For the sake of brevity, however, I will not discuss Rawls's view here.
} 
beneficence framed by (E) and a duty to engage in institutional reforms geared to the implementation of $(\mathrm{G})$ may make similar demands in terms of the quantity of effort and time and resources that agents must devote to them under nonideal circumstances. But there is a qualitative difference between the two duties that is likely to have quantitative consequences down the road. The two duties demand different kinds of things. The duty to engage in institutional reform has the peculiarity of being focused on the introduction of institutional schemes securing fair and efficient mechanisms that, to the extent that they are introduced, diminish the requirements on particular individuals. (E) does not clearly do this. ${ }^{48}$ Thus, from a transitional standpoint that is concerned with both issues of fairness and the urgency of the claims of the Destitute, shifting from informal beneficence to the pursuit of institutional justice seems warranted, as the temporal trajectories of these duties are likely to be different. The latter is directly concerned with targeting conditions of feasibility for less demanding schemes of aid.

The second issue then arises whether a demanding view of the duty to contribute to institutional reform would be infeasible because it might demand serious restrictions on individuals' special responsibilities toward those who are near and dear to them. This is a difficult issue that deserves more detailed discussion than I can provide here. For the purposes of this paper we can respond, however, by saying three things. First, in its rejection of (D) (the "Intolerably Intrusive" Principle), a contractualist approach makes room for special relationships and responsibilities. It does not, however, take them as unqualified "trumping cards." Their boundaries must undergo impartial assessment. An agent A can reasonably reject B's unrestrained pursuit of a special relationship with C when it leads to harm to A or to neglecting A's needs when these are urgent and C's are not. ${ }^{49}$ Second, it should be noticed that if the demands of institutional reform are infeasible because they collide with people's

${ }^{48}$ Someone might say that a principle of beneficence can itself lead us to endorse schedules of institutional reform if they are shown to be the most efficient way of improving the condition of those in need. This would involve, however, a broader use of the term "beneficence" than the one used here. It would make beneficence roughly equivalent to a general category of moral basic positive duties. Something like this seems to be the view pursued by Liam Murphy in "Institutions and the Demands of Justice," Philosophy and Public Affairs 27 (1999): 251-91. I agree with Murphy insofar as I also do not think that there is a radical discontinuity between moral and institutional considerations. 1 think, however, that it is good to sharpen the distinction between informal assistance ("beneficence" in the narrow sense used in this paper) and institutional mechanisms of aid ("justice" in the narrow sense used in this paper).

${ }^{49}$ For a detailed discussion of this and related issues, see Arash Abizadeh and Pablo Gilabert, "Is There a Genuine Tension between Cosmopolitan Egalitarianism and Special Responsibilities?" Philosophical Studies (forthcoming). See also Kwame Anthony Appiah, Cosmopolitanism: Ethics in a World of Strangers (New York: Norton, 2006), chap. 10. 
pursuit of their special relationships, then so would the demands of informal beneficence framed by (E). Thus, this consideration would not provide reasons for favoring (E) (the relevant alternative) over duties oriented toward the implementation of $(\mathrm{G})$.

Third, and most importantly, we should again emphasize the dynamic nature of trajectories of institutional reform by taking a transitional standpoint. For the reasons given above, trajectories focused on (G) are specifically geared to generating schemes of discharge of basic positive duties that fairly and efficiently give proper attention to the demands of all those affected. These trajectories may involve, as we saw, successive steps. Even if today it is not feasible to expect people to fully honor their basic positive duties of justice, we can start by entertaining some feasible reforms that could generate conditions of feasibility for further reforms. Let me conclude with an example of what some moral philosophers in research universities can do. Some of the reasons why many people do not choose to engage in institutional reform are that the moral arguments for it are not clear, and that the actual institutional mechanisms envisaged have not been carefully specified. We should not, however, take these circumstances as parametric factors that we must assume to be fixed. Whether compelling moral arguments circulate and whether careful institutional proposals exist partly depends on whether we actually try to produce them. It would not be a bad idea, for example, for moral philosophy professors in research universities to lead the creation of interdisciplinary projects devoted to conceptual and empirical exploration of issues of global justice and poverty relief. This may be a feasible first step to make feasible what does not seem now to be so.

\author{
Pablo Gilabert \\ Department of Philosophy \\ Concordia University, Montreal \\ pablo.gilabert@concordia.ca
}

\footnotetext{
${ }^{50}$ I thank Arash Abizadeh, Roberto Gargarella, Kai Nielsen, Lisa Rivera, Jesse Tomalty, and two anonymous referees and the Editors of Social Theory and Practice for comments and suggestions on earlier drafts of this paper. Earlier versions of this paper were presented at the 2006 Congress of the Canadian Philosophical Association (Toronto), the Centro de Investigaciones Filosóficas (Buenos Aires), and the Universidad Torcuato Di Tella (Buenos Aires). 1 thank the participants in these events for helpful questions and criticisms. Research for this paper has been supported by grants from the Social Sciences and Humanities Research Council of Canada and the Fonds Québécois de la recherche sur la société et la culture.
} 
Copyright of Social Theory \& Practice is the property of Florida State University / Dept. of Philosophy and its content may not be copied or emailed to multiple sites or posted to a listserv without the copyright holder's express written permission. However, users may print, download, or email articles for individual use. 